\title{
Controle de CAPIM-ARroz (Echinochloa spp.) em Função de MÉtodos de ManeJo Na CUltura do ARROZ IRRIGADO ${ }^{1}$
}

\author{
Control of Echinochloa spp. as a Function of Management Methods in Flooded Rice
}

\author{
PINTO, J.J.O. ${ }^{2}$, GALON, L. ${ }^{3}$, DAL MAGRO, T. ${ }^{4}$, PROCÓPIO, S.O. ${ }^{5}$, CONCENÇO, G. ${ }^{3}$, PINHO, C.F. ${ }^{6}$ \\ e FERREIRA, E.A. ${ }^{3}$
}

\begin{abstract}
RESUMO - Objetivou-se com este trabalho avaliar a eficácia do herbicida penoxsulam em função do início da irrigação permanente e da época de sua aplicação e dose no controle de capim-arroz (Echinochloa crusgalli e E. colona), bem como sua seletividade à cultura do arroz irrigado, cultivar Qualimax-1. O experimento foi conduzido a campo em delineamento experimental de blocos ao acaso com quatro repetições, no esquema fatorial $2 \times 3 \times 4$, representando épocas de início da irrigação por inundação (21 e 30 dias após a emergência - DAE), épocas de aplicação (pré-emergência e pós-emergência inicial e tardia) e doses do herbicida penoxsulam $\left(0,18,36\right.$ e $\left.72 \mathrm{~g} \mathrm{ha}^{-1}\right)$, respectivamente. As variáveis avaliadas foram o controle de capim-arroz, a fitotoxicidade do herbicida à cultura e a produtividade de grãos do arroz. A antecipação do início da irrigação permanente na lavoura aumentou a eficiência do penoxsulam para controle de capim-arroz, porém o atraso na entrada de água foi parcialmente compensado pelo aumento na dose do herbicida. Ao atrasar o início da irrigação na lavoura, ocorreu diminuição na produtividade de grãos, independentemente da época de aplicação e da dose de penoxsulam.
\end{abstract}

Palavras-chave: Oryza sativa, dose, entrada de água, estádio de aplicação, penoxsulam.

\begin{abstract}
The objective of this work was to evaluate the efficiency of the herbicide penoxsulam as a function of the start of permanent irrigation and time and rate of application, in controlling Echinochloa crusgalli and E. colona, as well as its selectivity to the rice culture, $c v$. Qualimax 1. The trial was conducted under field conditions in a completely randomized block design, in a factorial scheme $2 \times 3 \times 4$ with four replications. The factorial scheme were the irrigation starting times (21 and 30 days after emergence-DAE), application times (pre-emergence and early and late post-emergence) and penoxsulam rates $\left(0,18,36\right.$ and $\left.72 \mathrm{~g} h^{1}\right)$. The evaluated variables were Echinochloa control, rice plant phytotocixity, and rice grain yield. Early irrigation increased the efficiency of penoxsulam in Echinochloa control; however, the effect of late irrigation was partially offset by the increase in the penoxsulam rates. When irrigation started late, reduced grain yield was observed independently time and rate of herbicide application.
\end{abstract}

Keywords: Oryza sativa, rate, field water input, application stage, penoxsulam

1 Recebido para publicação em 25.10.2007 e na forma revisada em 24.4.2008.

2 Engo-Agr ${ }^{0}$, M.Sc., Professor da Faculdade de Agronomia Eliseu Maciel da Universidade Federal de Pelotas - FAEM/UFPel, <jesuspinto@terra.com.br>. Caixa postal 354, 96010-900, Capão do Leão-RS; ${ }^{3}$ Engo-Agro ${ }^{\circ}$, Doutorando do Programa de PósGraduação em Fitotecnia da Universidade Federal de Viçosa - UFV, 36570-000-Viçosa-MG; <galonleandro@ig.com.br>. (autor para correspondência); ${ }^{4}$ Enga-Agra ${ }^{\text {a }}$, Doutoranda do Programa de Pós-Graduação em Fitossanidade da UFPel, Caixa postal 354, 96010-900, Capão do Leão-UFPel; ${ }^{5}$ Pesquisador da Embrapa Tabuleiros Costeiros, 49025-040, Aracaju-SE, <procopio@cpatc.embrapa.br>; ${ }^{6}$ Aluna de graduação de agronomia da FAEM/UFPel. 


\section{INTRODUÇÃO}

A ocorrência de plantas daninhas nas lavouras de arroz irrigado representa um dos fatores limitantes ao potencial de produtividade da cultura, sendo as perdas variáveis em função da espécie vegetal, da população infestante, do cultivar de arroz e das práticas de manejo adotadas pelos orizicultores (Galon et al., 2007a, b).

Entre as plantas daninhas que infestam as lavouras de arroz irrigado encontra-se o capim-arroz, de elevada importância, pois ocorre com grande freqüência e distribuição nas regiões produtoras do cereal (Andres et al., 2007). $\mathrm{O}$ efeito negativo de sua presença para a cultura do arroz deve-se à alta capacidade de competição por recursos limitantes, à dificuldade de controle, ao acamamento das plantas da cultura, à dificuldade de colheita, à depreciação da qualidade do produto, ao abrigo de pragas, à diminuição do valor comercial das áreas cultivadas e, também em algumas situações, à ocorrência de biótipos resistentes a determinados herbicidas (Kissmann, 1997; LopezMartinez et al., 1999).

A principal forma de interferência que se estabelece entre as plantas de capim-arroz e arroz irrigado no Rio Grande do Sul (RS) e de Santa Catarina é a competição pelos recursos luz e nutrientes (Andres \& Machado, 2004; SOSBAI, 2005). No Estado do RS, diversos trabalhos quantificaram a perda direta na produtividade de grãos de arroz em sistema irrigado, devido à competição com plantas de capim-arroz. Os resultados demonstram perdas de produtividade variáveis de 4 a $90 \%$ em função da densidade de plantas daninhas, do cultivar utilizado e das épocas de entrada de água na lavoura (Menezes \& Ramírez, 2003; Galon et al., 2007a, b; Agostinetto et al., 2007).

Independentemente do sistema de cultivo do arroz, o controle químico é a principal alternativa para o manejo de capim-arroz, pela sua eficiência e praticidade (Andres \& Machado, 2004). Além do uso de herbicidas, o manejo da água na lavoura é de elevada importância no controle de plantas daninhas, pois o sucesso na produção de arroz irrigado, seja do ponto de vista econômico ou do desenvolvimento da própria cultura, é dependente do momento de início da irrigação. No entanto, a irrigação da lavoura de arroz está intimamente relacionada ao sistema de cultivo adotado, pois ele determina diferenças na época de início e fim da irrigação, manejo e consumo de água e, principalmente, no preparo do solo.

No Estado do RS, o início da irrigação por inundação da lavoura de arroz tradicionalmente ocorre aos 30 dias após a emergência da cultura. Contudo, a irrigação logo após a aplicação dos herbicidas pode auxiliar no manejo das plantas daninhas e melhorar a produtividade de grãos da cultura, já que o atraso de entrada de água na lavoura possibilita a reinfestação, sobretudo de espécies pertencentes à família Poaceae, como o capim-arroz (Kissmann, 1997). De acordo com Agostinetto et al. (2007), o atraso da entrada de água na lavoura de arroz irrigado em 1, 10 e 20 dias após a aplicação dos herbicidas ocasionou perdas de produtividade de 8,10 e $11 \%$, respectivamente, na presença de 1 planta de capimarroz $\mathrm{m}^{-2}$. Por outro lado, deve-se ressaltar que o momento de início da irrigação pode interferir no nível de intoxicação de herbicidas à cultura. Normalmente, a imediata irrigação após a aplicação de herbicidas pode incrementar os danos às plantas de arroz, podendo reduzir a produtividade de grãos (Concenço et al., 2006a).

Atualmente, o uso de herbicidas com atividade residual prolongada no solo possibilita retardar o início da irrigação, pois a inibição da germinação e emergência de plantas daninhas que seria exercida pela água é substituída pela ação do herbicida. No entanto, a extensão desse período depende do produto, da dose empregada, das espécies infestantes, dos níveis de infestação e das condições edafoclimáticas, podendo variar de 15 a 30 dias após a aplicação, dependendo do manejo adotado (Andres \& Machado, 2004).

Quando a aplicação de herbicidas é feita com as plantas daninhas nos estádios de um a três folhas (pós-inicial), a eficácia aumenta, proporcionando nível aceitável de controle (Jordan et al., 1997) e menor concorrência das plantas infestantes com a cultura do arroz, desde que logo em seguida também se inicie a irrigação, para que a lâmina de água evite a reinfestação (SOSBAI, 2005). 
O controle precoce de plantas daninhas, em especial do capim-arroz, associado ao início da irrigação logo após a aplicação dos herbicidas, em sistema convencional, pode aumentar a eficiência do controle químico, dependendo das condições climáticas específicas do ano. Caso haja menor eficiência de controle do capim-arroz, aliado à entrada de água tardia na lavoura, as plantas de arroz serão menos eficientes na formação de grãos, podendo diminuir a produtividade, além de proporcionar aumento da fase de desenvolvimento vegetativo da cultura do arroz irrigado e, por conseguinte, do seu ciclo (Ramirez et al., 1999).

Em geral, os efeitos da interferência de plantas daninhas sobre as culturas ocorrem com maior intensidade no período inicial do ciclo de desenvolvimento, não sendo diferente para a cultura do arroz irrigado, sendo a competição com o capim-arroz mais pronunciada no período inicial do ciclo da cultura (Johnson et al., 1998). De acordo com Noldin (1999), realizar mais precocemente o controle químico de plantas daninhas pode ser uma estratégia para reduzir doses de herbicidas e, assim, causar menor impacto desses produtos no ambiente, bem como menores injúrias à cultura do arroz.

Objetivou-se com este trabalho avaliar a eficácia do herbicida penoxsulam em função da dose, do início da irrigação permanente, da época de controle de capim-arroz (Echinochloa crusgalli e E. colona) e da seletividade do herbicida à cultura do arroz irrigado, cultivar Qualimax 1.

\section{MATERIAL E MÉTODOS}

O experimento foi conduzido a campo, no Centro Agropecuário da Palma (CAP), da Universidade Federal de Pelotas (UFPel), Município de Capão do Leão-RS. O solo da área experimental é classificado como Planossolo Hidromórfico Eutrófico solódico com textura arenosa, pertencente à Unidade de Mapeamento Pelotas (Embrapa, 1999). A correção do pH e a adubação de manutenção foram realizadas conforme as recomendações para a cultura do arroz irrigado (SOSBAI, 2005).

$\mathrm{O}$ experimento foi instalado em sistema convencional de semeadura, com uma aração e gradagem. O delineamento utilizado foi de blocos ao acaso, com tratamentos dispostos em esquema de parcelas subsubdivididas, com quatro repetições. A semeadura do arroz, cultivar Qualimax-1, foi realizada mecanicamente com uma semeadora-adubadora, com 13 linhas espaçadas em $0,17 \mathrm{~m}$, proporcionando densidade média de 85 sementes por metro linear e 400 sementes aptas $\mathrm{m}^{-2}$. Os tratamentos constaram de épocas de início da irrigação (21 e 30 dias após a emergência da cultura DAE), épocas de aplicação do herbicida penoxsulam (pré-emergência, pós-emergência inicial e tardia) e doses do herbicida $(0,18,36$ e $72 \mathrm{~g} \mathrm{ha}^{-1}$ ). A aspersão dos herbicidas, em pósemergência, ocorreu com as plantas de capimarroz com duas a três folhas em um a três afilhos, respectivamente, para as aplicações inicial e tardia. Neste trabalho utilizaram-se as doses de penoxsulam de 18 e $36 \mathrm{~g} \mathrm{ha}^{-1}$, abaixo das recomendadas para controle de capimarroz, e a de $72 \mathrm{~g} \mathrm{ha}^{-1}$, superior aos $48 \mathrm{~g} \mathrm{ha}^{-1}$ registrados para controle dessa planta daninha na cultura do arroz irrigado (Brasil, 2008), pois a meta era estudar a viabilidade da redução da dose recomendada em função dos diferentes manejos adotados com a cultura do arroz, em que variaram os estádios de aplicação, as diferentes épocas de manejo da irrigação e as doses herbicidas.

A aplicação do herbicida foi realizada com o auxílio de pulverizador costal, pressurizado por gás carbônico $\left(\mathrm{CO}_{2}\right)$, operando com pressão constante de $210 \mathrm{kPa}$, acoplado a uma barra contendo cinco pontas de pulverização do tipo "leque" (110.02), distanciadas em 0,5 m, proporcionando a aplicação de volume de calda de $150 \mathrm{~L} \mathrm{ha}^{-1}$. O levantamento botânico da área experimental foi realizado aos $45 \mathrm{DAE}$, apresentando densidade populacional média de 630 plantas $\mathrm{m}^{-2}$ de capim-arroz.

O herbicida foi pulverizado um dia após a semeadura (DAS) para os tratamentos em préemergência, aos 20 DAS para os aplicados em pós-emergência inicial e aos 25 DAS para os de pós-emergência tardia. As condições ambientais locais médias para as aplicações em pré-emergência, pós-emergência inicial e pós-emergência tardia foram, respectivamente: temperaturas do ar de 21,3, 22,5 e $22,8^{\circ} \mathrm{C}$; UR de 83, 85 e $87 \%$; e ventos de 2,5, 2,8 e $3,1 \mathrm{~km} \mathrm{~h}^{-1}$. Nas aplicações do herbicida, 
o solo estava superficialmente seco e a temperatura a $5,0 \mathrm{~cm}$ de profundidade era de 23,3 , 23,8 e $24,2^{\circ} \mathrm{C}$ para a aplicação de pré-emergência, pós-emergência inicial e pós-emergência tardia, respectivamente. Com relação à precipitação no período compreendido entre os meses de novembro, dezembro e janeiro, observou-se a ocorrência de 91,5, 28,6 e $70,4 \mathrm{~mm}$ de chuva mensais, respectivamente, com média diária de 3,1, 0,9 e 2,3 mm.

As variáveis avaliadas foram: controle de capim-arroz aos 15 e 30 dias após a aplicação dos tratamentos (DAT) e na pré-colheita; seletividade do herbicida à cultura do arroz aos 15 e 30 DAT; e produtividade de grãos na pós-colheita do arroz. Todas as avaliações de controle ou de injúria à cultura foram realizadas visualmente por dois avaliadores, utilizando-se a escala percentual, em que a nota zero $(0 \%)$ correspondeu a nenhum controle das plantas daninhas ou dano à cultura, e a nota cem (100\%), à morte de todas as plantas (Burrill, 1976). A quantificação da produtividade de grãos do arroz foi obtida pela colheita das paniculas na área útil de cada parcela $\left(3,6 \mathrm{~m}^{2}\right)$, quando o teor de umidade dos grãos atingiu aproximadamente $22 \%$. Após a pesagem dos grãos, determinou-se sua umidade, sendo a produtividade padronizada para $13 \%$ de umidade.

Os dados foram submetidos à análise de variância. Sendo os efeitos significativos, os efeitos de início da irrigação permanente foram avaliados pelo teste $t(p \leq 0,05)$, e a época de aplicação do herbicida penoxsulam, pelo teste de Tukey $(p \leq 0,05)$. Os efeitos do fator dose foram estudados por modelos de regressão linear e não-linear, conforme segue:

$$
\begin{aligned}
& Y=a\left(1-e^{-b x}\right) \\
& Y=a+b x
\end{aligned}
$$

em que: $\mathrm{a}=$ valor máximo estimado para a variável-resposta; $b=$ inclinação da reta ou curva; $\mathrm{x}=$ dose do herbicida penoxsulam $\left(\mathrm{g} \mathrm{ha}^{-1}\right) ; \mathrm{e}=$ constante.

\section{RESULTADOS E DISCUSSÃO}

Para as variáveis controle de capim-arroz, fitotoxicidade do herbicida penoxsulam à cultura e produtividade de grãos de arroz, verificou-se interação entre os fatores estudados. Aos 15 DAT, para a entrada de água na lavoura aos $21 \mathrm{DAE}$, observou-se, de modo geral, que houve influência da época de aplicação do herbicida. Quando a sua aplicação foi efetuada mais tardiamente, menor foi o controle de capim-arroz, mesmo com o aumento da dose do herbicida (Tabela 1). No entanto, quando a entrada de água foi aos $30 \mathrm{DAE}$, essa tendência somente foi verificada para a dose de $18 \mathrm{~g} \mathrm{ha}^{-1}$. Aos 30 DAT não foi observado efeito de entrada de água e épocas de aplicação do herbicida, à exceção da dose de $18 \mathrm{~g} \mathrm{ha}^{-1}$ com entrada de água aos $30 \mathrm{DAE}$, em que a aplicação de préemergência apresentou melhor controle da planta daninha. Esse efeito provavelmente esteja associado ao estádio de desenvolvimento da planta daninha, pois, quando submetida à aplicação de herbicidas em baixas doses, temse comprometimento no controle (Andres \& Machado, 2004).

Entretanto, na avaliação de controle efetuada na pré-colheita do arroz, observou-se que, independentemente de dose e épocas de aplicação do herbicida, não houve diferenças quando a entrada de água foi realizada precocemente, ou seja, mesmo com baixas doses e aplicações tardias de herbicidas associadas à entrada de água antecipada nas lavouras de arroz irrigado, o efeito pode ser compensado pelo controle exercido pela água de irrigação, que atuou como uma barreira física, evitando assim a emergência/refluxo ou desenvolvimento de capim-arroz (Freitas, 2004). No entanto, ao irrigar a lavoura tardiamente, foi observado efeito das doses dos herbicidas e também das épocas de sua aplicação sobre as plantas de capim-arroz; em geral, as duas menores doses do penoxsulam (18 e $36 \mathrm{~g} \mathrm{ha}^{-1}$ ) apresentaram baixo controle da planta daninha com o atraso das épocas de aplicação do herbicida e das entradas de água na lavoura (Tabela 1).

Os resultados expostos na Tabela 1 permitem inferir que na maior dose $\left(72 \mathrm{~g} \mathrm{ha}^{-1}\right)$ o penoxsulam proporcionou maior eficácia de controle do capim-arroz, independentemente do momento da entrada de água na lavoura ou do estádio de aplicação do herbicida em todas as demais épocas de avaliação. Uma exceção a essa tendência é a avaliação efetuada aos 15 DAT, com a entrada de água aos $21 \mathrm{DAE}$ e 
Tabela 1 - Controle de capim-arroz na cultura do arroz irrigado em função da dose de penoxsulam, da época de aplicação do herbicida e da época de entrada de água na lavoura. CAP-UFPel, Capão do Leão-RS

\begin{tabular}{|c|c|c|c|c|c|c|c|}
\hline \multirow{3}{*}{$\begin{array}{l}\text { Dose } \\
\left(\mathrm{g} \mathrm{ha}^{-1}\right)\end{array}$} & \multirow{3}{*}{$\begin{array}{c}\text { Época de aplicação } \\
\text { do herbicida }\end{array}$} & \multicolumn{6}{|c|}{ Controle $(\%)$} \\
\hline & & \multicolumn{2}{|c|}{$15 \mathrm{DAT}^{1 /}$} & \multicolumn{2}{|c|}{$30 \mathrm{DAT}$} & \multicolumn{2}{|c|}{ Pré-colheita } \\
\hline & & $21 \mathrm{DAE}^{2 /}$ & $30 \mathrm{DAE}$ & $21 \mathrm{DAE}$ & $30 \mathrm{DAE}$ & $21 \mathrm{DAE}$ & $30 \mathrm{DAE}$ \\
\hline \multirow{3}{*}{0} & Pré-emergência ${ }^{4 /}$ & $0,0 \mathrm{Aa}^{3 /}$ & $0,0 \mathrm{Aa}$ & $0,0 \mathrm{Aa}$ & $0,0 \mathrm{Aa}$ & $0,0 \mathrm{Aa}$ & $0,0 \mathrm{Aa}$ \\
\hline & Pós-emergência inicial $\left.\right|^{5 /}$ & $0,0 \mathrm{Aa}$ & $0,0 \mathrm{Aa}$ & $0,0 \mathrm{Aa}$ & $0,0 \mathrm{Aa}$ & $0,0 \mathrm{Aa}$ & $0,0 \mathrm{Aa}$ \\
\hline & Pós-emergência tardia ${ }^{6 /}$ & $0,0 \mathrm{Aa}$ & $0,0 \mathrm{Aa}$ & $0,0 \mathrm{Aa}$ & $0,0 \mathrm{Aa}$ & $0,0 \mathrm{Aa}$ & $0,0 \mathrm{Aa}$ \\
\hline \multirow{3}{*}{18} & Pré-emergência & $65 \mathrm{ABb}$ & $83 \mathrm{Aa}$ & $91 \mathrm{Aa}$ & $93 \mathrm{Aa}$ & $83 \mathrm{Aa}$ & $64 \mathrm{Ab}$ \\
\hline & Pós-emergência inicial & $73 \mathrm{Aa}$ & $65 \mathrm{Ba}$ & $89 \mathrm{Aa}$ & $75 \mathrm{Bb}$ & $94 \mathrm{Aa}$ & $19 \mathrm{Cb}$ \\
\hline & Pós-emergência tardia & $58 \mathrm{Ba}$ & $34 \mathrm{Cb}$ & $83 \mathrm{Aa}$ & $44 \mathrm{Cb}$ & $92 \mathrm{Aa}$ & $34 \mathrm{Bb}$ \\
\hline \multirow{3}{*}{36} & Pré-emergência & $86 \mathrm{Aa}$ & $84 \mathrm{Aa}$ & $96 \mathrm{Aa}$ & $94 \mathrm{Aa}$ & $90 \mathrm{Aa}$ & $68 \mathrm{Bb}$ \\
\hline & Pós-emergência inicial & $87 \mathrm{Aa}$ & $83 \mathrm{Aa}$ & $95 \mathrm{Aa}$ & $93 \mathrm{Aa}$ & $99 \mathrm{Aa}$ & $60 \mathrm{Bb}$ \\
\hline & Pós-emergência tardia & $60 \mathrm{Bb}$ & $84 \mathrm{Aa}$ & $98 \mathrm{Aa}$ & $94 \mathrm{Aa}$ & $100 \mathrm{Aa}$ & $80 \mathrm{Ab}$ \\
\hline \multirow{3}{*}{72} & Pré-emergência & $98 \mathrm{Aa}$ & $87 \mathrm{Ab}$ & $100 \mathrm{Aa}$ & $97 \mathrm{Aa}$ & $99 \mathrm{Aa}$ & $85 \mathrm{Ab}$ \\
\hline & Pós-emergência inicial & $83 \mathrm{Ba}$ & $88 \mathrm{Aa}$ & $99 \mathrm{Aa}$ & $98 \mathrm{Aa}$ & $100 \mathrm{Aa}$ & $93 \mathrm{Aa}$ \\
\hline & Pós-emergência tardia & $70 \mathrm{Cb}$ & $89 \mathrm{Aa}$ & $100 \mathrm{Aa}$ & $99 \mathrm{Aa}$ & $100 \mathrm{Aa}$ & $96 \mathrm{Aa}$ \\
\hline
\end{tabular}

1/ Dias após a aplicação dos tratamentos herbicidas; ${ }^{2} /$ Épocas de entrada de água na lavoura em dias após a emergência da cultura; ${ }^{3 /}$ Médias seguidas por mesmas letras maiúsculas na coluna, dentro de cada época de entrada de água na lavoura em diferentes épocas e dentro de doses de aplicação do herbicida, e por mesma letra minúscula na linha, dentro de entrada de água, não diferiram entre si pelo teste de Tukey $(\mathrm{p} \leq 0,05) ; 4 /, 5 /$ e ${ }^{6 /}$ Aplicação do herbicida efetuada aos 1,20 e 25 dias após a semeadura da cultura do arroz, respectivamente.

nas épocas de aplicação de pós-emergência. Salienta-se com isso que os melhores controles observados na maior dose podem ter ocorrido em função do efeito residual do herbicida, e não somente das épocas de sua aplicação ou de início da irrigação (Concenço et al., 2006a).

Analisando o efeito da dose de penoxsulam no controle de capim-arroz aos 15 DAT, observou-se que, a fim de compensar o atraso no início do período de irrigação permanente no arroz, é necessário incrementar a dose do herbicida para a manutenção do nível de controle de capim-arroz (Figura 1). Na mesma avaliação de controle, não houve efeito entre as modalidades de aplicação do herbicida em estudo. Além disso, observou-se que nas menores doses do herbicida os melhores resultados de controle foram verificados com a entrada de água antecipadamente, enquanto nas maiores doses a entrada de água mais tardia possibilitou melhores niveis de controle. Isso poderá decorrer do efeito residual do produto, que é parcialmente anulado a partir do momento da entrada da água, devido à maior lixiviação ou percolação (Andréa \& Luchini, 2002).

$\mathrm{Na}$ avaliação de controle realizada aos 30 DAT, os resultados assemelham-se aos observados aos 15 DAT (Figura 2). No entanto, quando o penoxsulam foi aplicado em pósemergência tardia, observou-se maior prejuízo no controle de capim-arroz na combinação de baixa dose do herbicida com o atraso do início do período de irrigação, em comparação às demais modalidades de aplicação. Convém salientar ainda que, ao aplicar o herbicida em préemergência ou em pós-emergência inicial, ocorre estabilização do controle na dose próxima a $20 \mathrm{~g} \mathrm{ha}^{-1}$, fato este não observado quando se aplica esse herbicida tardiamente. Provavelmente, essa situação deve-se em parte ao fato de o capim-arroz estar em estádio de maior suscetibilidade ao herbicida, ou seja, em estádio inicial de desenvolvimento (Berti et al., 1996).

$\mathrm{Na}$ avaliação de controle de capim-arroz realizada na pré-colheita, à exceção de $18 \mathrm{~g}$ ha ${ }^{1}$, houve bom controle da planta daninha com aplicação do herbicida em pré-emergência, se comparado às aplicações em pós-emergência, sendo observada estabilização a partir dessa dose. No entanto, quando a aplicação foi realizada em pós-emergência, somente foram observados niveis aceitáveis de controle quando a entrada de água ocorreu aos 21 DAE (Figura 3). 

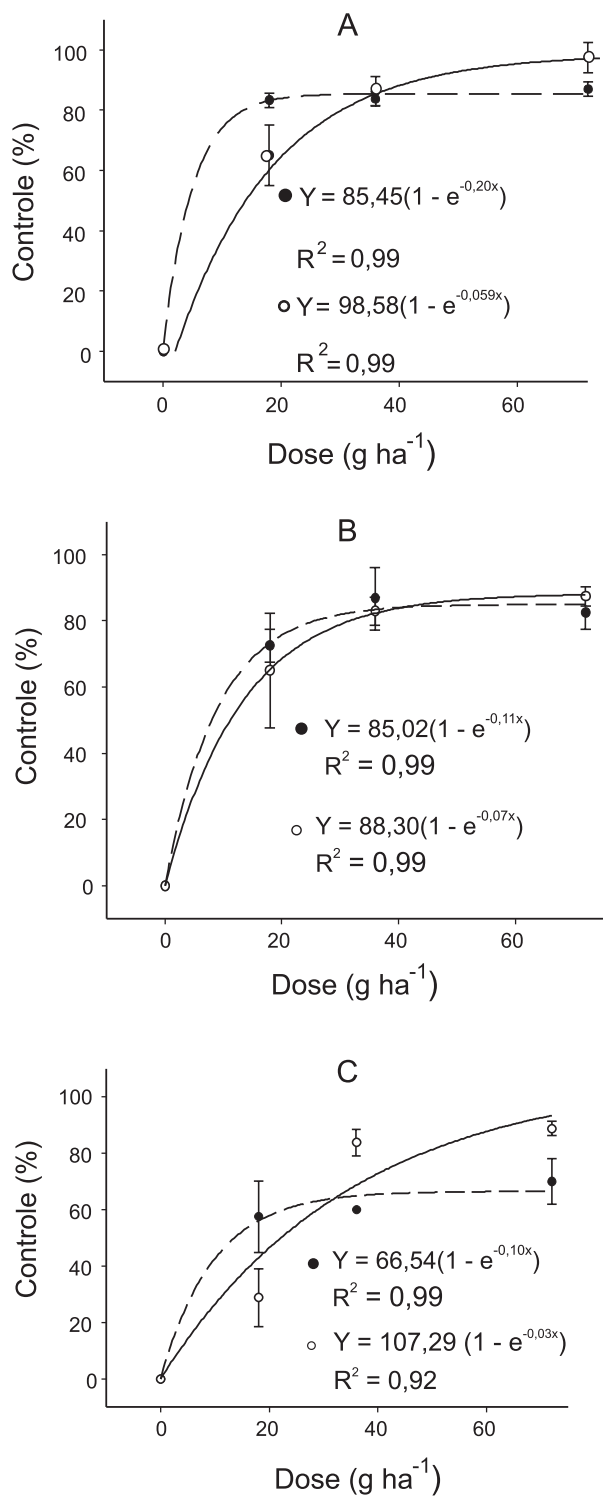

Figura 1 - Controle de capim-arroz na cultura do arroz irrigado aos 15 DAT, em função de épocas de aplicações do herbicida penoxsulam: pré-emergência (A), pós-emergência inicial (B) e pós-emergência tardia $(C)$ e duas entradas de água na lavoura $(21$ e $030 \mathrm{DAE})$.

É possivel inferir, de maneira geral, que se pode usar a menor dose de penoxsulam associada à entrada de água antecipadamente (21 DAE) para obter niveis de controle semelhantes, ou então atrasar a entrada de água na lavoura e utilizar maiores doses do herbicida. Resultados semelhantes foram observados por Concenço et al. (2006b), que, trabalhando com capim-arroz, relataram controle eficiente dessa planta daninha com os herbicidas
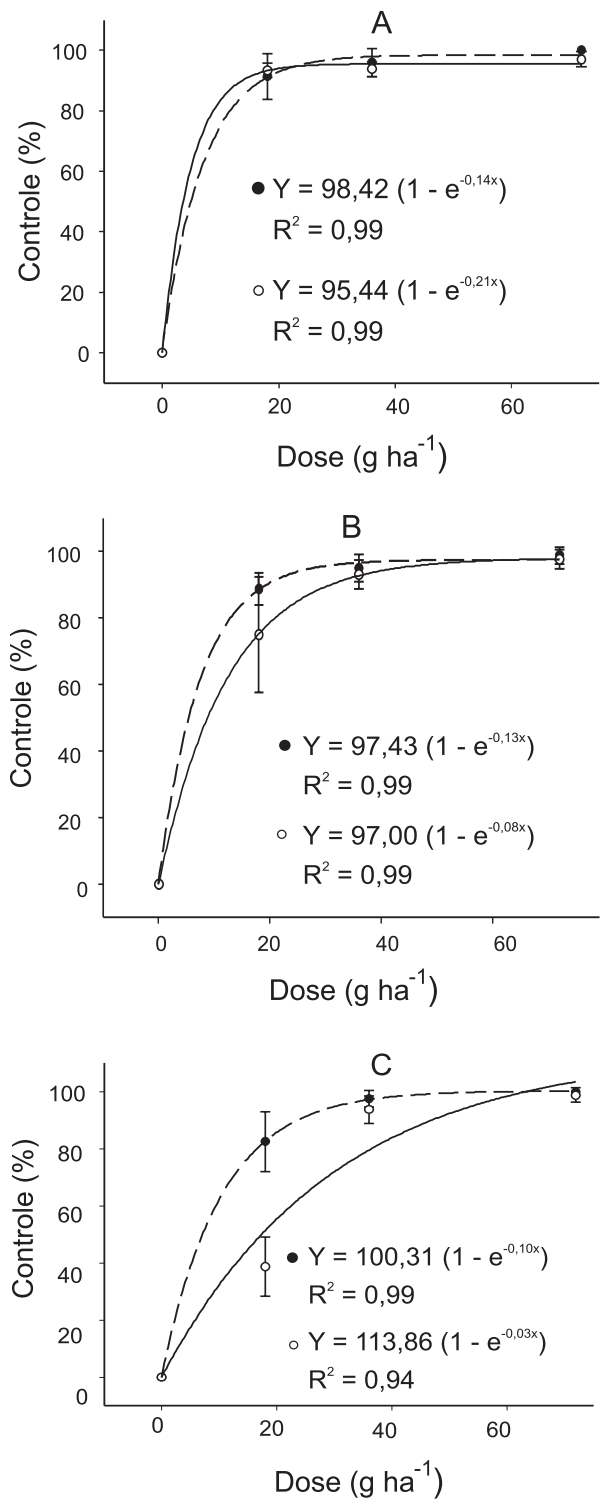

Figura 2 - Controle de capim-arroz na cultura do arroz irrigado aos 30 DAT, em função de épocas de aplicações do herbicida penoxsulam: pré-emergência (A), pós-emergência inicial (B) e pós-emergência tardia $(C)$ e duas entradas de água na lavoura $(\bullet 21$ e o $30 \mathrm{DAE})$.

penoxsulam e clomazone quando o procedimento do início da irrigação ocorreu aos 19 e 24 DAE, em diferentes doses testadas.

Com relação à variável fitotoxicidade, avaliada aos 15 DAT, observou-se injúria inferior a $5 \%$ para a dose de $36 \mathrm{~g} \mathrm{ha}^{-1}$ de penoxsulam em qualquer momento de aplicação e entrada de água, enquanto atinge $11,3 \%$ nessas mesmas condições na última avaliação (Tabela 2). 


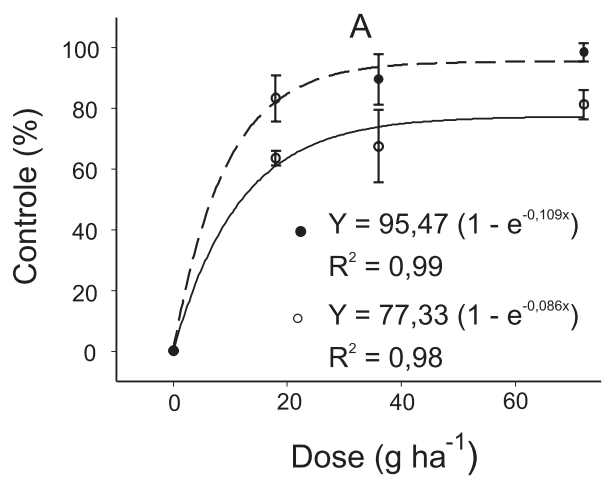

B
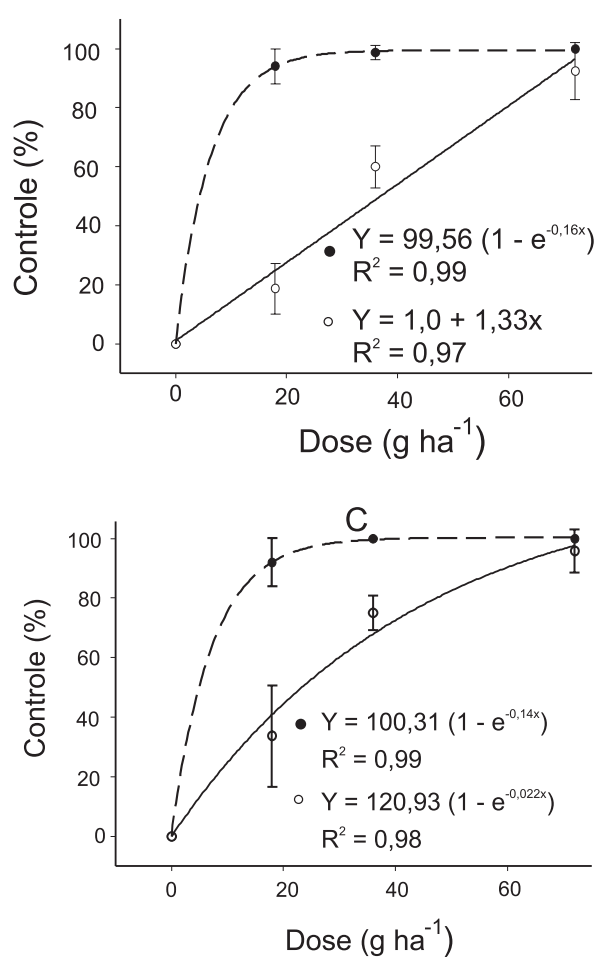

Figura 3 - Controle de capim-arroz na cultura do arroz irrigado na pré-colheita, em função de épocas de aplicações do herbicida penoxsulam: pré-emergência $(\mathrm{A})$, pós-emergência inicial (B) e pós-emergência tardia (C) e duas entradas de água na lavoura $(21$ e $030 \mathrm{DAE})$.

Na maior dose testada (superior à recomendada/registrada), os danos máximos ocasionados pelo herbicida penoxsulam foram de $10 \%$ na primeira avaliação, alcançando valores máximos próximos de $21 \%$ na avaliação realizada aos 30 DAT. Na maior dose testada, os danos máximos ocasionados pelo herbicida penoxsulam foram de $10 \%$ na avaliação realizada aos 15 DAT, alcançando valores máximos próximos de $21 \%$ aos 30 DAT. Deve-se destacar que, aos 15 DAT, ocorreram diferenças na variável fitotoxicidade na última época de aplicação do penoxsulam para a segunda entrada de água na lavoura, na dose de $36 \mathrm{~g} \mathrm{ha}^{-1}$; isso pode ter ocorrido em função da presença de maior umidade no solo, o que potencializa os efeitos fitotóxicos dos herbicidas (Concenço et al., 2006b). Na avaliação de fitotoxicidade realizada aos 30 DAT, observou-se que houve maior injúria à cultura ao se aplicar o herbicida em pré-emergência, na primeira entrada de água na lavoura, para a maior dose do herbicida (Tabela 2). Corroborando esses resultados, Concenço et al. (2006b) e Andres et al. (2007), ressaltam que a inundação da lavoura próximo à aplicação de herbicidas com efeitos residuais e em doses elevadas pode potencializar os efeitos fitotóxicos à cultura.

Quando se avaliaram os niveis de fitotoxicidade à cultura em função da dose do herbicida penoxsulam, foi possível inferir que não houve efeito de início da irrigação por inundação e que a injúria aumentou moderadamente com o acréscimo da dose do herbicida (Tabela 2 e Figuras 4 e 5). Os percentuais atingidos pela injúria foram de $15 \%$ na avaliação aos 15 DAT e próximo a $20 \%$ na avaliação aos 30 DAT, à exceção da aplicação em pré-emergência, na avaliação aos 15 DAT, em que não houve efeito de dose e a intensidade dos sintomas observados não foi além de 5\% (Figuras 4 e 5). Resultados similares quanto à fitotoxicidade do herbicida penoxsulam às plantas de arroz já haviam sido relatados por Concenço et al., (2006b).

Com relação à produtividade de grãos, houve efeito da época de início da irrigação (Tabela 2 e Figura 6). Em todas as doses testadas do herbicida penoxsulam foram observadas maiores produtividades com entrada de água aos 21 DAE (Tabela 2). No entanto, observouse que, na média das entradas de água, a dose de $18 \mathrm{~g} \mathrm{ha}^{-1}$ demonstrou produtividade de grãos inferior à observada nas doses de 36 e $72 \mathrm{~g} \mathrm{ha}^{-1}$. As baixas produtividades observadas em todos os momentos de aplicação do herbicida com o retardo na entrada de água, ou seja, aos 30 $\mathrm{DAE}$, deve-se provavelmente à reinfestação da lavoura em função da ausência do efeito complementar da água na ação do herbicida e, também, ao menor efeito residual em decorrência da baixa dose utilizada. Nas doses de 
Tabela 2 - Fitotoxicidade e produtividade de grãos da cultura do arroz irrigado em função da dose de penoxsulam, da época de aplicação do herbicida e da época de entrada de água na lavoura. CAP-UFPel, Capão do Leão-RS

\begin{tabular}{|c|c|c|c|c|c|c|c|}
\hline \multirow{3}{*}{$\begin{array}{l}\text { Dose } \\
\left(\mathrm{g} \mathrm{ha}^{-1}\right)\end{array}$} & \multirow{3}{*}{$\begin{array}{c}\text { Época de aplicação do } \\
\text { herbicida }\end{array}$} & \multicolumn{4}{|c|}{ Fitotoxicidade (\%) } & \multirow{2}{*}{\multicolumn{2}{|c|}{ Produtividade $\left(\mathrm{t} \mathrm{ha}^{-1}\right)$}} \\
\hline & & \multicolumn{2}{|c|}{$15 \mathrm{DAT}^{1 /}$} & \multicolumn{2}{|c|}{30 DAT } & & \\
\hline & & $21 \mathrm{DAE}^{2 /}$ & $30 \mathrm{DAE}$ & $21 \mathrm{DAE}$ & $30 \mathrm{DAE}$ & $21 \mathrm{DAE}$ & $30 \mathrm{DAE}$ \\
\hline \multirow{3}{*}{0} & Pré-emergência ${ }^{4 /}$ & $0,0 \mathrm{Aa}^{3 /}$ & $0,0 \mathrm{Aa}$ & $0,0 \mathrm{Aa}$ & $0,0 \mathrm{Aa}$ & $0,82 \mathrm{Aa}$ & $\overline{0,47 \mathrm{Aa}}$ \\
\hline & Pós-emergência inicial ${ }^{5 / 1}$ & $0,0 \mathrm{Aa}$ & $0,0 \mathrm{Aa}$ & $0,0 \mathrm{Aa}$ & $0,0 \mathrm{Aa}$ & $0,82 \mathrm{Aa}$ & $0,47 \mathrm{Aa}$ \\
\hline & Pós-emergência tardia $^{6 /}$ & $0,0 \mathrm{Aa}$ & $0,0 \mathrm{Aa}$ & $0,0 \mathrm{Aa}$ & $0,0 \mathrm{Aa}$ & $0,82 \mathrm{Aa}$ & $0,47 \mathrm{Aa}$ \\
\hline \multirow{3}{*}{18} & Pré-emergência & $1,3 \mathrm{Aa}$ & $0,0 \mathrm{Aa}$ & $0,0 \mathrm{Aa}$ & $0,0 \mathrm{Aa}$ & $5,06 \mathrm{Aa}$ & $2,90 \mathrm{Ab}$ \\
\hline & Pós-emergência inicial & $0,0 \mathrm{Aa}$ & $1,3 \mathrm{Aa}$ & $1,3 \mathrm{Aa}$ & $6,3 \mathrm{Aa}$ & $5,75 \mathrm{Aa}$ & $1,51 \mathrm{Bb}$ \\
\hline & Pós-emergência tardia & $0,0 \mathrm{Aa}$ & $0,0 \mathrm{Aa}$ & $1,3 \mathrm{Aa}$ & $0,0 \mathrm{Aa}$ & $6,04 \mathrm{Aa}$ & $1,70 \mathrm{Bb}$ \\
\hline \multirow{3}{*}{36} & Pré-emergência & $0,0 \mathrm{Aa}$ & $0,0 \mathrm{Aa}$ & $4,0 \mathrm{Aa}$ & $2,5 \mathrm{Ba}$ & $6,44 \mathrm{Aa}$ & $3,24 \mathrm{Bb}$ \\
\hline & Pós-emergência inicial & $2,5 \mathrm{Aa}$ & $0,0 \mathrm{Aa}$ & $9,0 \mathrm{Aa}$ & $4,0 \mathrm{ABa}$ & $5,44 \mathrm{Aa}$ & $3,17 \mathrm{Bb}$ \\
\hline & Pós-emergência tardia & $0,0 \mathrm{Ab}$ & $5,0 \mathrm{Aa}$ & $10 \mathrm{Aa}$ & $11,3 \mathrm{Aa}$ & $5,45 \mathrm{Aa}$ & $4,44 \mathrm{Ab}$ \\
\hline \multirow{3}{*}{72} & Pré-emergência & $6,3 \mathrm{Aa}$ & $4,0 \mathrm{Aa}$ & $21,3 \mathrm{Aa}$ & $10 \mathrm{Ab}$ & $6,00 \mathrm{Aa}$ & $4,21 \mathrm{Ab}$ \\
\hline & Pós-emergência inicial & 7,5 Aa & 4,0 Aa & $15 \mathrm{Aa}$ & $11,3 \mathrm{Aa}$ & $4,86 \mathrm{Ba}$ & $3,89 \mathrm{Ab}$ \\
\hline & Pós-emergência tardia & $10 \mathrm{Aa}$ & $9,0 \mathrm{Aa}$ & $19 \mathrm{Aa}$ & $18 \mathrm{Aa}$ & $5,52 \mathrm{ABa}$ & $4,02 \mathrm{Ab}$ \\
\hline
\end{tabular}

1/ Dias após a aplicação dos tratamentos herbicidas; ${ }^{2}$ Épocas de entrada de água na lavoura em dias após a emergência da cultura; ${ }^{3}$ Médias seguidas por mesmas letras maiúsculas na coluna, dentro de cada época de entrada de água na lavoura em diferentes épocas e dentro de doses de aplicação do herbicida, e por mesma letra minúscula na linha, dentro de entrada de água, não diferiram entre si pelo teste de Tukey $(\mathrm{p} \leq 0,05) ; \underline{4}, \underline{5}$ e ${ }^{6 /}$ Aplicação do herbicida efetuada aos 1,20 e 25 dias após a semeadura da cultura do arroz, respectivamente.

36 e $72 \mathrm{~g} \mathrm{ha}^{-1}$, o penoxsulam foi capaz de manter niveis de produtividade mesmo com entrada de água aos $30 \mathrm{DAE}$, sendo superiores aos observados nas mesmas condições com aplicação de $18 \mathrm{~g} \mathrm{ha}^{-1}$. Contudo, a produtividade observada com entrada de água aos 30 DAE foi sempre inferior à observada com a entrada de água aos $21 \mathrm{DAE}$, independentemente da dose e do estádio de aplicação do herbicida (Tabela 2).

Com relação ao efeito de doses para a variável produtividade de grãos de arroz, observou-se que, ao aplicar o herbicida em préemergência, ela teve acréscimo até a dose de $36 \mathrm{~g} \mathrm{ha}^{-1}$, quando a entrada de água ocorreu aos 21 DAE. Quando a entrada de água ocorreu aos $30 \mathrm{DAE}$, a estabilização de produtividade foi obtida em doses similares, porém a produtividade média de grãos foi inferior à obtida com a entrada de água aos 21 DAE (Figura 6). Com a aplicação do herbicida em pós-emergência, foram obtidas produtividades máximas de grãos a partir da menor dose avaliada com a entrada de água aos $21 \mathrm{DAE}$, enquanto na entrada de água aos $30 \mathrm{DAE}$ a produtividade de grãos foi sempre inferior e mais dependente da dose do herbicida (Figura 6). Deve-se salientar que, independentemente da dose ou época de aplicação do herbicida, com entrada da água na lavoura aos $21 \mathrm{DAE}$, há incremento - em média, de $57 \%$ - na produtividade de grãos de arroz, comparativamente aos 30 DAE (Tabela 2). Resultados semelhantes foram observados por Andres et al. (2007) e Freitas (2004), com a redução da dose de herbicidas residuais. Freitas (2004) relata queda de 20\% na produtividade de grãos do arroz em função do atraso da irrigação de 20 para $35 \mathrm{DAE}$. Ainda de acordo com esse autor, a associação de herbicidas com efeito residual no solo pode proporcionar a manutenção nos niveis de produtividade de grãos, mesmo com o atraso na irrigação da lavoura.

Diante dos resultados expostos, é possivel concluir que o atraso do início da irrigação por inundação afeta significativamente a produtividade de grãos da cultura do arroz, independentemente da dose e época de aplicação do herbicida penoxsulam. A antecipação do início da irrigação por inundação aumenta a eficiência do penoxsulam para o controle de capim-arroz, e o atraso na entrada de água é parcialmente compensado pelo aumento na dose do herbicida. 

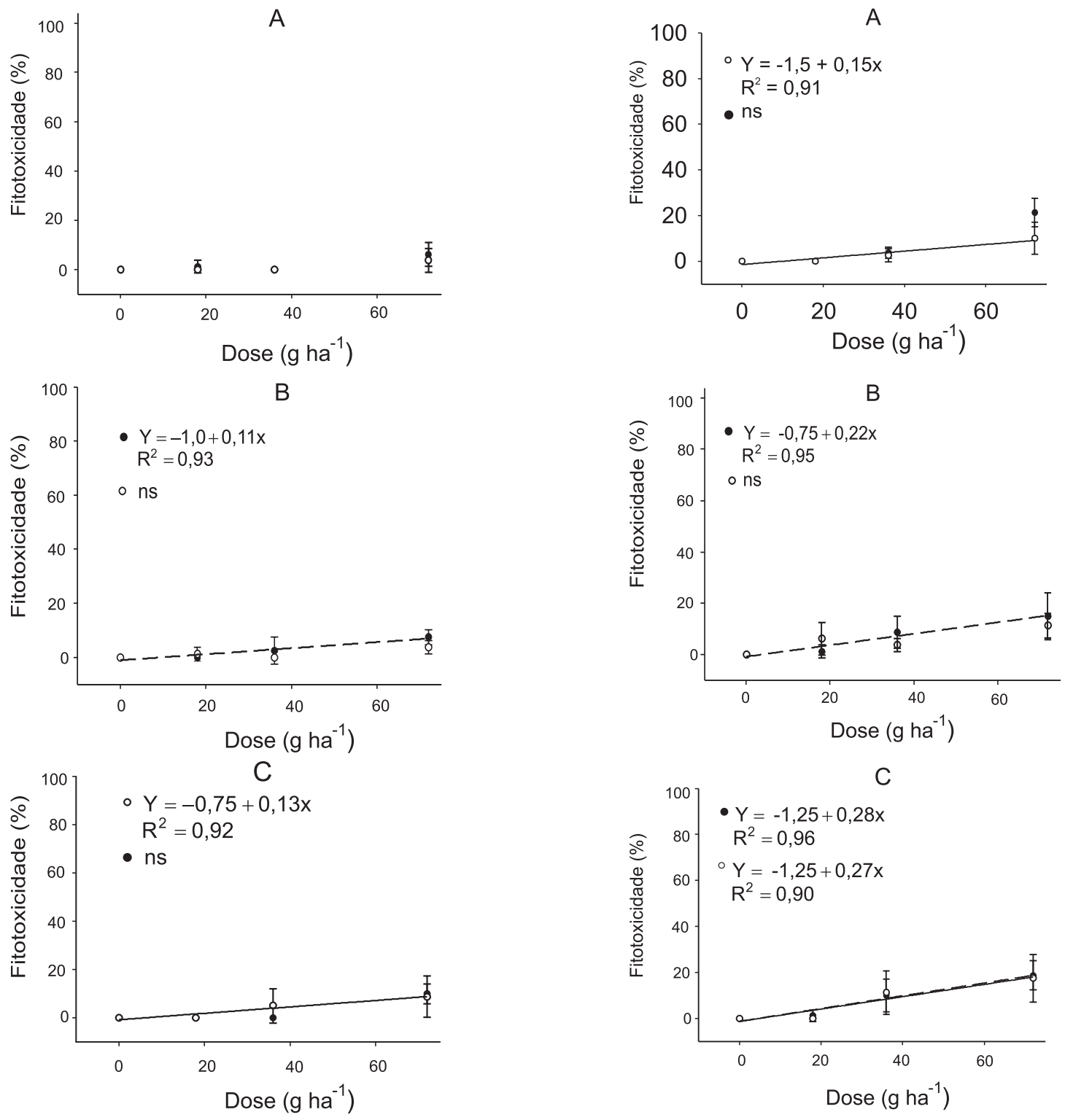

Figura 4 - Fitotoxicidade à cultura do arroz irrigado aos 15 DAT, em função de épocas de aplicações do herbicida penoxsulam: pré-emergência (A), pós-emergência inicial (B) e pós-emergência tardia $(C)$ e duas entradas de água na lavoura $(21$ e $\bigcirc 30 \mathrm{DAE})$.

Figura 5 - Fitotoxicidade à cultura do arroz irrigado aos 30 DAT, em função de épocas de aplicações do herbicida penoxsulam: pré-emergência (A), pós-emergência inicial (B) e pós-emergência tardia $(\mathrm{C})$ e duas entradas de água na lavoura $(\bullet 21$ e $030 \mathrm{DAE})$. 

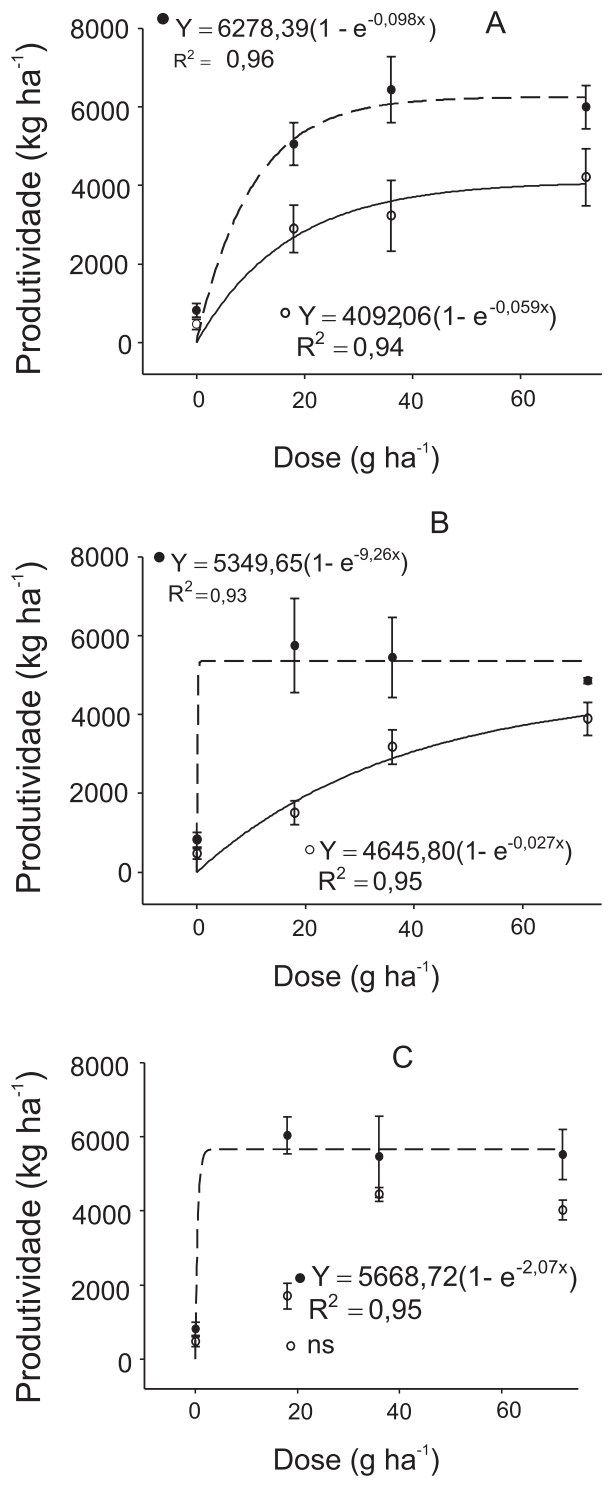

Figura 6 - Produtividade de grãos do arroz irrigado, em função de épocas de aplicações do herbicida penoxsulam: préemergência (A), pós-emergência inicial (B) e pós-emergência tardia (C) e duas entradas de água na lavoura $(21$ e o 30 DAE).

\section{LITERATURA CITADA}

AGOSTINETTO, D. et al. Interferência de capim-arroz (Echinochloa spp.) na cultura do arroz irrigado (Oryza sativa) em função da época de irrigação. Planta Daninha, v. 25, n. 4, p. 689-696, 2007.

ANDREA; M. M.; LUCHINI, L. C. Comportamento de pesticidas em solos brasileiros: a experiência do Instituto Biológico/SP. B. Inf. SBCS, v. 27, n. 2, p. 22-24, 2002.
ANDRES, A.; MACHADO, S. L. O. Plantas daninhas em arroz irrigado. In: GOMES, A. S.; MAGALHÃES Jr., A. M. (Eds.). Arroz irrigado no Sul do Brasil. Brasília: Embrapa Informação Tecnológica, 2004. p. 457-546.

ANDRES, A. et al. Desempenho da cultivar de arroz BRS Pelota e controle de capim-arroz (Echinochloa spp.) submetidos a quatro épocas de entrada de água após a aplicação de doses reduzidas de herbicidas. Planta Daninha, v. 25, n. 4, p. 859-867, 2007.

BERTI, A. et al. A new approach to determine when to control weeds. Weed Sci., v. 44, n. 3, p. 496-503, 1996.

BRASIL. Ministério da Agricultura e Pecuária. AGROFIT. Disponível em: $<$ htt://www.agricultura.gov.br $>$. Acesso em: 22 de abr. de 2008.

BURRILL, L. C.; CARDENAS, J. C.; LOCATELLI, E. Field manual for weed control research. Corvallis: Internaional Plant Protection Center, Oregon State University, 1976. 59 p.

CONCENÇO, G. et al. Controle de plantas daninhas em arroz irrigado em função de doses de herbicidas préemergentes e início da irrigação. Planta Daninha, v. 24, n. 2, p. 303-309, 2006a.

CONCENÇO, G. et al. Efeito de herbicidas aplicados em pré-emergência e momentos de início da irrigação no crescimento de plantas de arroz. Planta Daninha, v. 24, n. 2, p.295-301, 2006b

\section{EMPRESA BRASILEIRA DE PESQUISA} AGROPECUÁRIA - EMBRAPA. Centro Nacional de Pesquisa Agropecuária de Solos (Rio de Janeiro, RJ).

Sistema brasileiro de classificação de solos. Brasília Embrapa Produção de Informação; Rio de Janeiro: Embrapa Solos, 1999. $412 \mathrm{p}$

FREITAS, G. D. Desempenho do arroz (Oryza sativa L.) cultivar BRS Pelota e controle de capim-arroz (Echinochloa sp.) submetidos a quatro épocas de entrada de água após aplicação de doses reduzidas de herbicidas 2004. 54 f. Dissertação (Mestrado em Produção Vegetal) Universidade Federal de Pelotas, Pelotas, 2004.

GALON, L. et al. Níveis de dano econômico para decisão de controle de capim-arroz (Echinochloa spp.) em arroz irrigado (Oryza sativa). Planta Daninha, v. 25, n. 4, p. 709-718, $2007 \mathrm{a}$.

GALON, L. et al. Estimativa das perdas de produtividade de grãos em cultivares de arroz (Oryza sativa) pela interferência do capim-arroz (Echinochloa spp.). Planta Daninha, v. 25, n. 3, p. 697-707, 2007b.

JOHNSON, D. E. et. al. The influence of rice plant type of the effect on weed competition on Oryza sativa and Oryza glaberrima. Weed Res., v. 38, p. 207-216, 1998. 
JORDAN, D. L. et al. Comparison of graminicides applied at equivalent costs in soybean (Glycine max). Weed

Technol., v. 11, n. 4, p. 804-809, 1997.

KISSMANN, K. G. Plantas infestantes e nocivas. 2.ed. São Paulo: BASF, 1997. Tomo I. 825 p.

LOPEZ-MARTINEZ, N. et al. Molecular markers indicate intraspecific variation in the control of Echinochloa spp. with quinclorac. Weed Sci., v. 47, n. 3, p. 310-315, 1999.

MENEZES, V. G.; RAMIREZ, H. Controle de capim arroz (Echinochloa crusgalli) e capim capivara (Hymenachne amplexicaulis) com o herbicida Clincher em arroz irrigado no sistema de cultivo pré-germinado. In: CONGRESSO BRASILEIRO DE ARROZ IRRIGADO, 3., REUNIÃO DA CULTURA DO ARROZ IRRIGADO, 25., 2003, Balneário Camboriú. Anais... Itajaí: EPAGRI, 2003. p. 507-509.
NOLDIN, J. A. Doses, épocas e formulações de 2,4-D em arroz irrigado. In: CONGRESSO BRASILEIRO DE ARROZ IRRIGADO, 1.; REUNIÃO DA CULTURA DO ARROZ IRRIGADO, 23., 1999, Pelotas. Anais... Pelotas: Embrapa Clima Temperado, 1999. p. 562-565.

RAMIREZ, H.; MENEZES, V. G; OLIVEIRA, J. C. S. Controle precoce de plantas daninhas e início da irrigaçào na cultura do arroz irrigado no sistema convencional. In:

CONGRESSO BRASILEIRO DE ARROZ IRRIGADO, 1; REUNIÃO DA CULTURA DO ARROZ IRRIGADO, 23., 1999, Pelotas. Anais... Pelotas: Embrapa Clima Temperado, p. $597-600$.

SOCIEDADE SUL-BRASILEIRA DE ARROZ IRRIGADO - SOSBAI. Arroz irrigado: recomendações técnicas da pesquisa para o Sul do Brasil. Santa Maria: Universidade Federal de Santa Maria, 2005. 159 p. 